\title{
INTENSIVE DISPERSION TECHNOLOGIES FOR EXTRACTION OF HUMIC SUBSTANCES FROM PEAT
}

\author{
Janis Sire \\ Maris Klavins \\ University of Latvia
}

\begin{abstract}
Humic substances are abundant in the environment and they can be isolated in preparative quantities from low rank coal, peat and soil. Traditionally for their isolation treatment with solutions of $\mathrm{NaOH}, \mathrm{KOH}$ or metal salts $\left(\mathrm{K}_{4} \mathrm{P}_{2} \mathrm{O}_{7}\right)$ has been used. The aim of this article is to apply intensive extraction technologies for isolation of humic acids from peat.

Used technologies provide opportunities to obtain peat humic substances with significantly higher yields and more rapidly than traditional boiling in alkalic solutions. During the treatment peat fibers are subjected to major destruction.
\end{abstract}

\section{KEYWORDS}

Humic substances; Ultrasound; Cavitation; Peat

\section{INTRODUCTION}

Humic substances are a general category of naturally occurring, biogenic, heterogeneous organic substances that can generally be characterized as being yellow to black in color, of high molecular weight, and refractory [1]. Humic substances are an abundant ingredient of aquatic and soil organic matter as well as sedimentary (sapropel, gyttja) and fossil deposits (peat and poorly humified coal). Sedimentary and fossil carbon containing deposits are a significant source of humic substances. It has been estimated that only peat can be a source of up to $500 \mathrm{Gt} \mathrm{C}$ of humic acids of industrial value for their production [2]. Extraction of humic substances from their potential sources requires quite intensive treatment. Most widely extraction with $\mathrm{NaOH}$ and $\mathrm{KOH}$ at elevated temperatures has been used $[3,4,5]$ as well as other extractants. To increase yields stirring and repeated treatment of source material is suggested [6]. In the same time yields of humic substances often are low, their destruction during the extraction process can take place and voluminous wastes are formed.

Recently several technologies has been developed, at first suggesting industrially relevant approaches to increase treatment intensity of the extraction process, but also adding chemical and physical impacts and supporting discontinuous extraction process. Among technologies prospective for extraction of humic substances from peat can be suggested treatment with ultrasound, plasma and electrical discharge, cavitation. Cavitation, electric pulse reactors and sonification with ultrasound has not been applied for extraction of humic substances with 
preparative aims. In the same time similar approaches are applied in chemical synthesis [7, 8] even at industrial scale.

Cavitation, electric pulse reactors and sonification with ultrasound has been used for extraction from vegetable pulp. Electric discharges in pulp provide a high rate and level of extraction of substances soluble in water from vegetables or ore. The results of electropulse extraction of proteins and vitamins from specific kinds of ores are well documented $[9,10]$. Sonochemical treatment has been applied also in environmental technologies for decontamination of polluted sites. [11].

The aim of this article is to apply intensive extraction technologies for isolation of humic acids from peat. In this study to analyze impacts of intensive stirring technologies two ultrasound baths has been used with differing treatment energy as well as home made hydrodynamic cavitation reactor providing intensive bubble formation and electric pulse reactor operating with coal electrodes and discharge at $18 \mathrm{kV}$.

\section{MATERIALS AND METHODS}

\section{Extraction of humic substances from peat}

Four different extraction methods were used in this research:

1. The extraction with heating the extraction environment was performed;

2. Two ultrasound baths with volume 5 liters and power $0.27 \mathrm{~kW}$ and with volume $2 \mathrm{l}$ and power $0.07 \mathrm{~kW}$;

3. Experimental devices of plasma discharge (power $17 \mathrm{kV}$ ) and cavitation.

The extractions were performed using different extractants $\left(\mathrm{NaOH}, \mathrm{KOH}\right.$ and $\left.\mathrm{K}_{4} \mathrm{P}_{2} \mathrm{O}_{7}\right)$ and after selected time periods $(1,5,10,20,30,40,60,80,100,120$ minutes) samples of the extraction mixture has been taken, filtered off and in the filtrate using the Hach DR/2000 spectrophotometer the concentration of humic substances has been spectrophotometrically determined and the yields calculated.

\section{Extraction of humic acids}

After the extraction the amount of isolated residues of humic acids was determined. The isolated by precipitation at $\mathrm{pH} 2$ (acidification with $6 \mathrm{~N} \mathrm{HCl}$ ) humic acids was characterized by their elemental analysis (Carlo Erba Elemental Analyzer EA-1108).

\section{Scanning electron microscopy}

After extraction the residues of the peat were flushed with distilled water and dried. Then dry residues were fetched up to the sample holder and covered with the gold. Prepared samples were investigated using the JEOL ISM T-200 scanning electron microscope.

\section{RESULTS AND DISCUSSIONS}

In the research peat from Baložu peat bog (Latvia) was used and it had following properties (see Tables 1, 2). 
Table 1. Properties of the peat used in the research.

\begin{tabular}{lllllll}
\hline Peat source & Bog type & $\begin{array}{l}\text { Decomposition } \\
\text { degree, \% }\end{array}$ & $\begin{array}{l}\text { Ash } \\
\text { content, \% }\end{array}$ & Moisture, \% & $\begin{array}{l}\text { C } \\
\%\end{array}$ & content, \\
\hline $\begin{array}{l}\text { Baložu peat } \\
\text { bog }\end{array}$ & High type & 20 & 1,0 & 86,8 & 42,1 \\
\hline
\end{tabular}

Table 2. Botanical composition of the peats used in research.

\begin{tabular}{lll}
\hline Peat source & Botanical composition, & $\%$ \\
\hline & Sphagnum fuscum & 10 \\
Sphagnum angustifolium & 5 \\
Baložu peat bog & Scheuhzeria & 70 \\
& Erioph. vaginatum & 10 \\
& Shrubs (Oxycoccus) & 5 \\
\hline
\end{tabular}

Peat can be considered as a significant source of humic substances, but technologically relevant approaches for extraction of $\mathrm{HS}$ has not been studied. Usually extraction with $\mathrm{KOH}$ and $\mathrm{NaOH}$ has been used [12 - 15]. In this study four extraction approaches of humic substances from peat has been studied.

Traditional extraction methods are based on peat treatment with $\mathrm{NaOH}$ or $\mathrm{KOH}$ under mixing. Although these methods don't need special machinery or energy inputs, each extraction cycle takes comparatively long time (up to 24 hours) and high hydroxide concentrations, besides these extractions cannot be performed in flow mode. These methods are best suited for laboratory experiments, where small amounts of humic substances are needed. Since during the extraction with peat particles reacts only the extractants and the structure of the fibers is not degraded and the concentration of the extracted humic substances usually is low.

Thermal extraction method is slightly modified traditional method - it is based on thermal treatment of the extraction environment. It is possible to use this method in laboratory. As in traditional methods, this one uses high hydroxide concentrations, but the extraction time can be radically decreased (up to 4 hours)

Cavitation method is physical method, which is based on generation of high pressure which causes the formation of microscopical $(20-200 \mu \mathrm{m})$ gas bubbles in the extraction environment. Generating pressure pulsations these bubbles are breaking, causing local impacts, which can generate very high pressure $\left(4000-6000 \mathrm{~kg} / \mathrm{cm}^{2}\right)$ and temperature $(8000$ $-10000^{\circ} \mathrm{C}$ ). When these relatively high doses of kinetical and thermal energy are released in very small area, this causes complete destruction of peat fibers, as well as mixing of the extraction environment. These processes activate chemical reactions and can be performed in flow mode and the experimental device used in this survey can produce 200 liters of humic substances per hour.

Electrical discharge method is based on extraction of humic substances from peat in flow mode, by processing the peat - extractant $(\mathrm{KOH}$ or $\mathrm{NaOH})$ media with electrical discharge $(18 \mathrm{kV})$. Between the electrodes during discharge a plasma field with high temperatures and 
shock wave is formed, which performs the intensive mixing of the extraction media as well as degradation of peat fibres.

Ultrasound method is the sonification of hydroxide - raw material mixture in ultrasound bath, which has built-in ultrasound emitter. Ultrasound does not only corrode the peat fibers, but also provides intensive mixing of the extraction environment. Sonochemical treatment has been applied also in environmental technologies for decontamination of polluted sites [11]. In the research of Kim and Jung [16] has been proved that high intensity sonochemical treatment may reduce the molecular weight of humic substances.

Processes accomplishing the electric discharge and providing an extraction efficiency of extraction process in water irradiated by an ultrasonic wave depends on the characteristic of bubbles and thus depends on types of sonochemical reactors. When the acoustic amplitude is large at $20 \mathrm{kHz}$, the bubble content is mostly water vapor even at the end of the bubble collapse and the temperature inside a bubble at the collapse is relatively low. On the other hand, when the acoustic amplitude is relatively low, the bubble content is mostly noncondensable gas at the end of the bubble collapse and the bubble temperature is relatively high.

The comparison of the extraction kinetics shows (Figurel) the differences in the extraction efficiency of humic substances from peat.

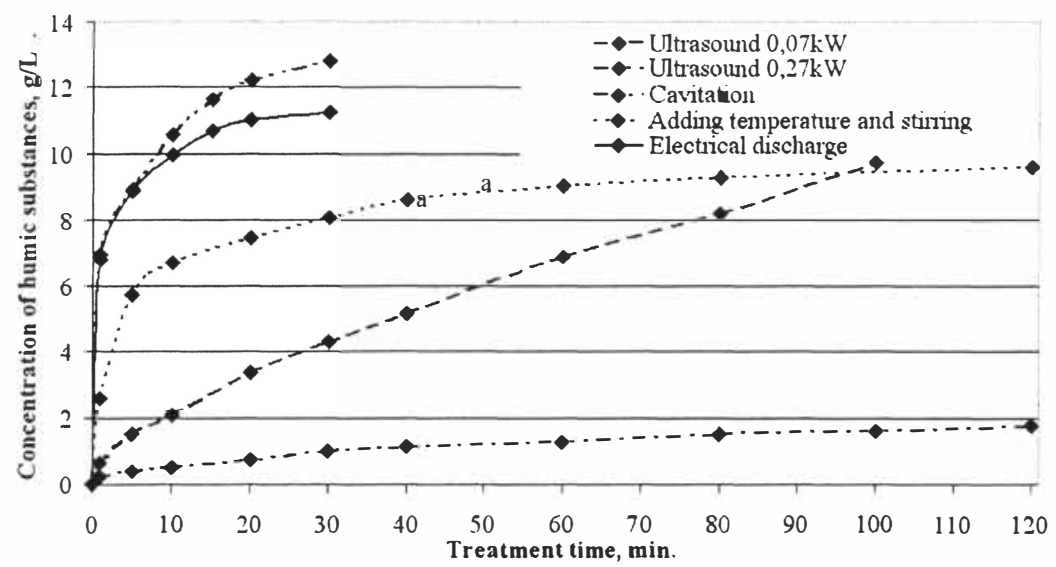

Figure 1. Comparison of different extraction methods using $1 \%$ sodium hydroxide

Comparatively high concentrations ( 11 and $13 \mathrm{~g} / \mathrm{L}$ respectively) can be attained in only 30 minutes using electrical discharge and cavitation methods, besides these methods are very effective - the concentrations about $7 \mathrm{~g} / \mathrm{L}$ can be attained during first extraction minute.

The effectiveness of the ultrasound is proportional to its power, but in general this process is much slower and less effective than two before mentioned methods. Using ultrasound with power $0.27 \mathrm{~kW}$ concentration similar to that attained with electrical discharge can be reached only after 100 minutes of treatment. 
Using the thermal treatment, the most effective are the first 20 minutes, when about $2 / 3$ of the humic substances are extracted, at the same time extraction longer than 60 minutes is ineffective, as the concentration of the humic substances increases very slow.

Extracting humic substances with cavitation method the highest yields can be obtained, when sodium hydroxide as an extractant is used (Figure 2) and in the first extraction minute twice higher concentrations than using $\mathrm{KOH}$ and even 25 times higher then using water can be achieved.

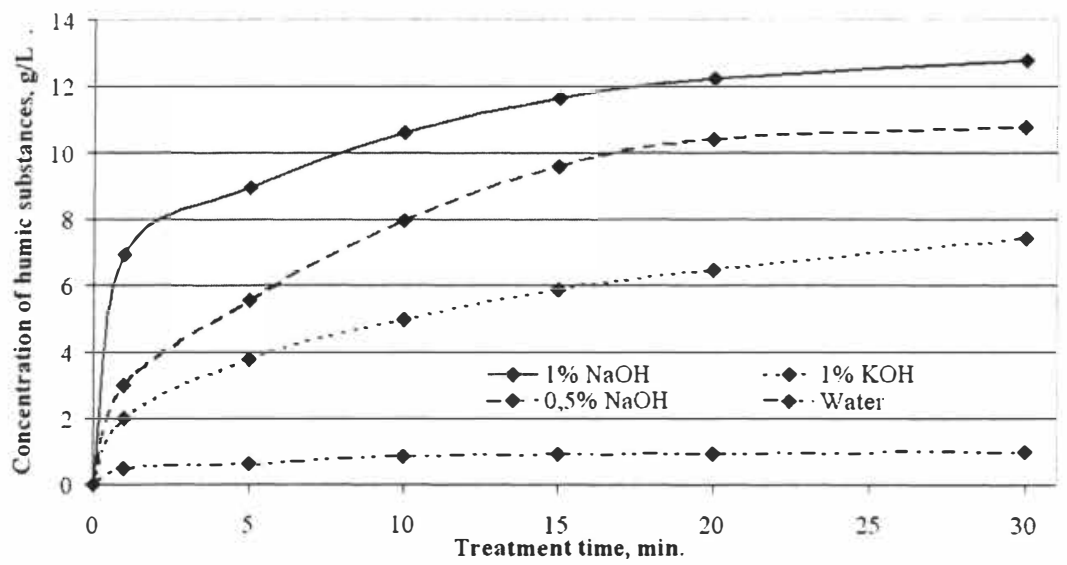

Figure 2. Comparison of different extractants, using cavitation technology

The effectiveness of ultrasound is closely related to its power - the ultrasound treatment with power $0.27 \mathrm{~kW}$ is 4 times more effective than one with $0.07 \mathrm{~kW}$, when $\mathrm{NaOH}$ is used (Figure 3).

When different extractants are compared, it can be seen, that sodium hydroxide is about $20 \%$ more effective than potassium hydroxide, but the application of the potassium pyrophosphate is ineffective, because the concentrations obtained are at least 5 times lower, than using $\mathrm{NaOH}$ or $\mathrm{KOH}$.

To evaluate the impact of different extraction methods on the peat fibers, the scanning electron microscopy was used. In Figure 4 can be seen peat fibers before treatment enlarged 150 times. There are clearly visible separate little divided plant parts, also their shape is unaltered. 


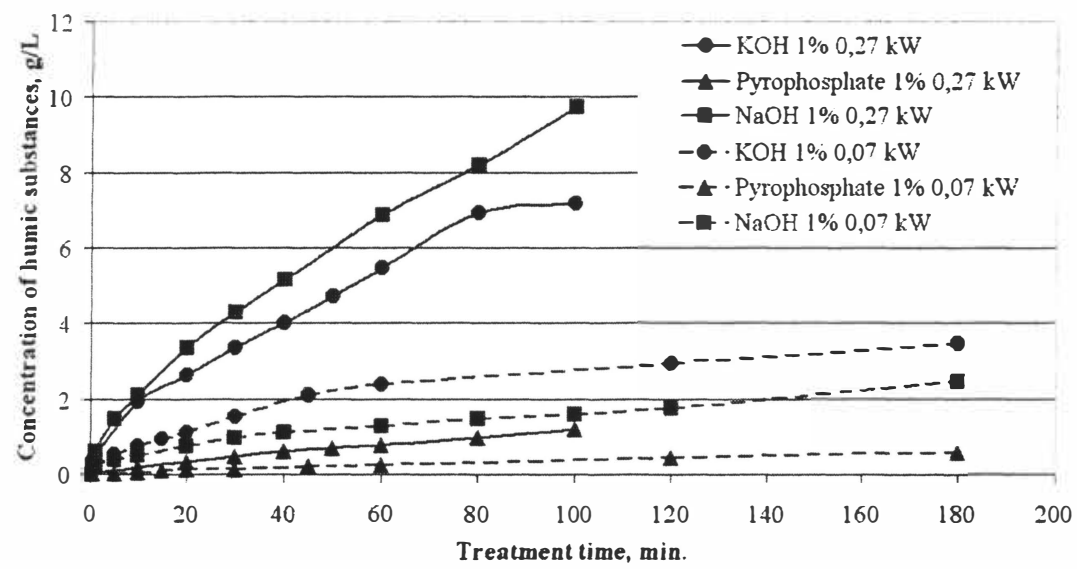

Figure 3. Comparison of different extractants, using different ultrasound baths

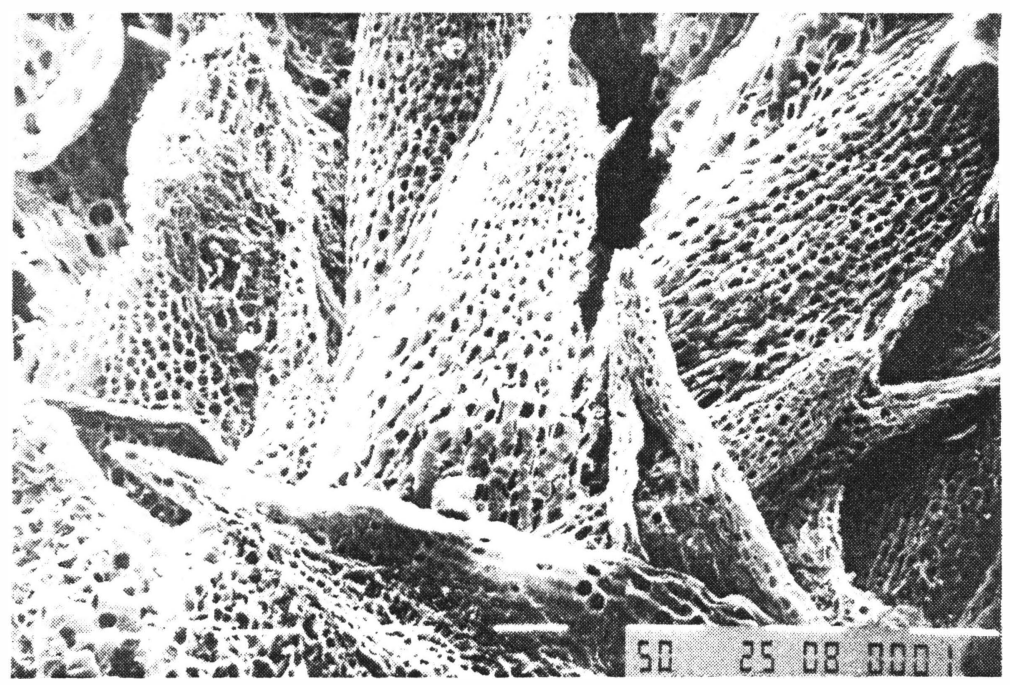

Figure 4. Peat fibers before treatment magnified 150 times.

The treatment with $1 \% \mathrm{NaOH}$ under elevated temperatures breaks down the structure of peat particles. In Figure 5,1 and 2, slightly changed form and shape of stomatas can be seen, as well as the surface layer of peat fibers has been broken and partly ripped off. 


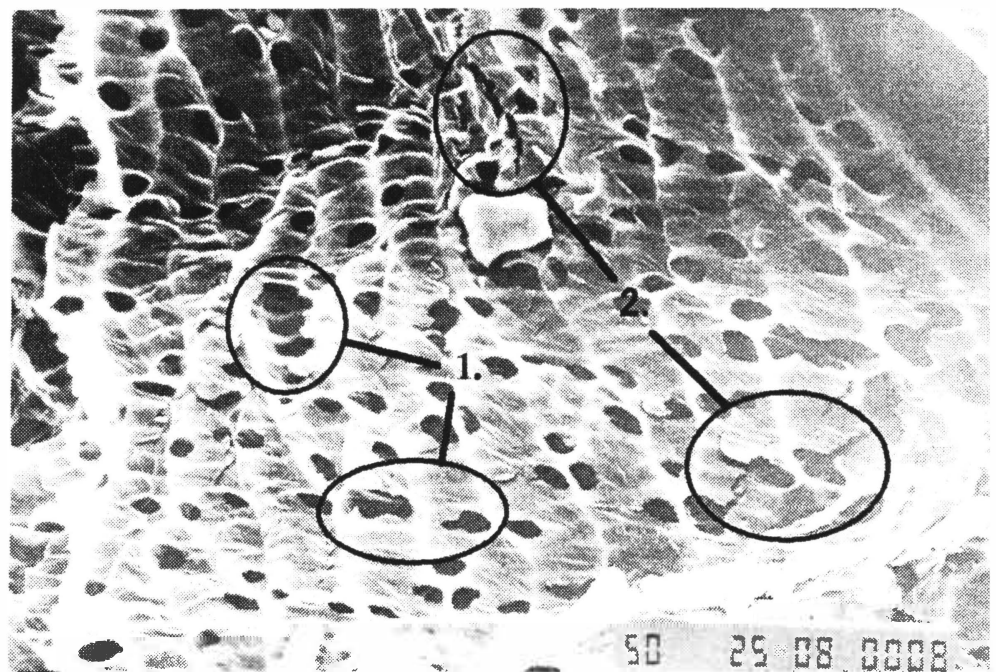

Figure 5. Peat fibers after 4 hours treatment with $1 \% \mathrm{NaOH}$ under elevated temperatures, magnified 600 times.

Processing peat with ultrasound, the degradation of its structural elements is promoted. Using the alkaline solution the solubility of the humic substances is increased, but on other hand the ultrasound additionally destroys the structural elements of peat, increasing the yield of humic substances. In Figure 6, 1. completely eroded surface layer as well as changed internal structures can be seen

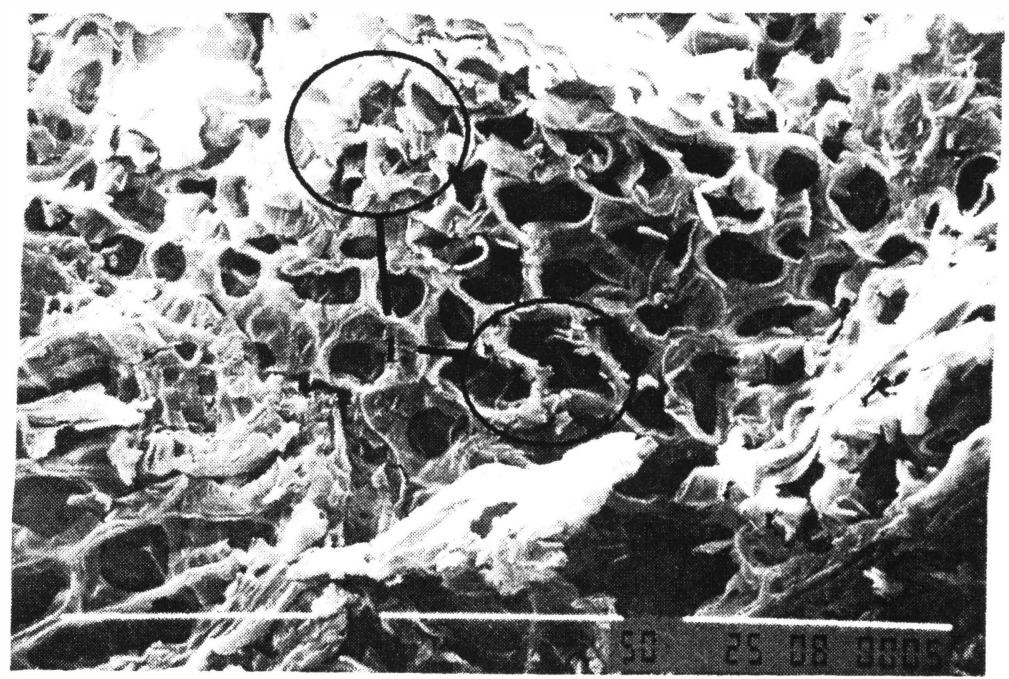

Figure 6. Peat fibers after 100 minutes treatment with ultrasound (power $0.27 \mathrm{~kW}$ ) using $1 \%$ $\mathrm{NaOH}$ as a extractant, magnified 600 times. 
Cavitation method is based on generation of microscopical gas bubbles in the extraction environment. When these bubbles are bursting, relatively high doses of kinetic and termic energy are released in very small area, which causes complete destruction of peat fibers. In figure 5. completely degraded peat structures can be seen. Only small part of peat fibers can be recognized (1. in Figure 7)

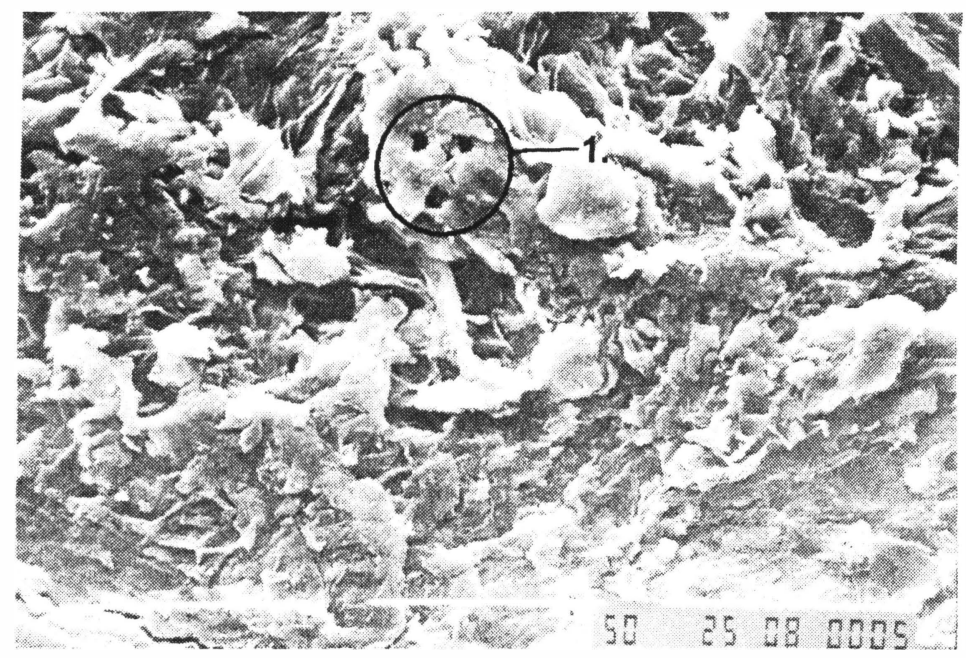

Figure 7. Peat fibers after 20 minutes treatment with cavitation method using $1 \% \mathrm{NaOH}$ as a extractant, magnified 600 times.

The obtained humic acids were analysed using elemental analysis, IR and UV spectroscopy. It was proved, that all extraction methods gave very similar results, the average can be seen in Table 3.

Table .3 Chemical composition of the peat humic acids.

\begin{tabular}{llll}
\hline Peat source & C content, $\mathrm{a} \%$ & $\mathrm{H}$ content, $\mathrm{a} \%$ & $\mathrm{~N}$ content, $\mathrm{a} \%$ \\
\hline Baložu peat bog & 56.39 & 4.21 & 1.02 \\
\hline
\end{tabular}

The effectiveness of extraction of humic substances is directly dependant from the capability to degrade the raw material, as well as from the extractant. The most effective are cavitation and electrical discharge methods, but most effective extractant is $\mathrm{NaOH}$, which gives approximately two times higher yields than $\mathrm{KOH}$ and provides much better results than all other extractants, like $\mathrm{K}_{4} \mathrm{P}_{2} \mathrm{O}_{7}$.

In large - scale production it is very important to achieve as high yields as possible using as far as possible low amount of aw materials, time and energy. For these criteria the best suited technologies are cavitation and electrical discharge methods, very perspective is also ultrasound method, but in this case it is very much power - dependent. 


\section{REFERENCES}

[1] Klaviņš, M., 1998. Aquatic humic substances: characterisation, structure and genesis. Latvian University, Riga, pp. 234.

[2] Markov, V.D., Olunin A.S., Ospennikova L.A., Skobeeva E.I., Khoroshev P.J., 1998. World peat resources. Nedra, Moscow.

[3] Ran, Y., Huang, W., Rao P.S., Liu D., Sheng G., Fu J., 2002. The role of condensed organic matter in the nonlinear sorption of hydrophobic organic contaminants by a peat and sediments. J. Environ. Qual. 31(6), 1953-1962.

[4] Ferreira, J.A., Martin-Neto, L., Vaz C.M.P., Regitano, J.B., 2002. Sorption Interactions between Imazaquin and a Humic Acid Extracted from a Typical Brazilian Oxisol. $J$. Environ. Qual.a 31(5), 1665a- 1670

[5] Martin-Neto, L, Traghetta, D. G., Vaz, C. M., Crestana, S., Sposito, G., 2001. On the interaction mechanisms of atrazine and hydroxyatrazine with humic substances. $J$. Environ. Qual. 30(2), 520 - 525

[6] Moreda-Piñeiro, A., Bermejo-Barrera, A., Bermejo-Barrera, P., 2004. New trends involving the use of ultrasound energy for the extraction of humic substances from marine sediments. Anal. Chim. Acta 524 (1-2), 97 - 107

[7] Gogate, P.aR., Pandit, A. B., 2005. A review and assessment of hydrodynamic cavitation as a technology for the future. Ultrason. Sonochem. 12(1-2), 21 a27

[8] Yasuai, K., Tuziuti, T., Iida, Y., 2005. Dependence of the characteristics of bubbles on types of sonochemical reactors. Ultrason. Sonochem. 12(1-2), 43-51

[9] Jiantao, H., Zhihong, S., Wenbao, C., 2004. Comparison of Microwave-Assisted and Ultrasound-Assisted Extraction for Determination of Main Water-Soluble Bioactive Constituents in Traditional Chinese Medicinal Preparation Tongmaichongji by HPLCDAD J. Liq. Chrom. \& Rel. Technol. 27(11), 1769-1784

[10] Kurets V., Lobanova G., Barskaya A., Boev S., 1999. Electropulse extraction of soluble in water substances from vegetable ore In: Pulsed Power Conference, 1999. Digest of Technical Papers. 12th IEEE International, 2, 1303 - 1304

[11] Jay, N. Meegoda, J. N., Veerawat, K., 2002. Ultrasound to decontaminate organics in dredged sediments. Soil Sediment Conatmin. 11(1), 91 - 116

[12] Martin-Neto, L, Traghetta, D. G., Vaz, C. M., Crestana, S., Sposito, G., 2001. On the interaction mechanisms of atrazine and hydroxyatrazine with humic substances. $J$. Environ. Qual. 30(2), $520-525$

[13] Olk, D. C., Cassman, K. G., Fan, T. W. M., 1995. Characterization of two humic acid fractions from a calcareous vermiculitic soil: implications for the humification process. Geoderma 65 (3-4), 195-208

[14] Kaschl, A., Römheld, V., Chen, Y., 2002. The influence of soluble organic matter from municipal solid waste compost on trace metal leaching in calcareous soils. The Science of The Total Environment 291 (1-3), 45-57

[15] Mahieu, N., Olk, D. C., Randall, E. W., 2002. Multinuclear magnetic resonance analysis of two humic acid fractions from lowland rice soils. J. Environ. Qual. 31(2), 421-30

[16] Kim, I.K., Jung, O.J., 2001. Sonochemical decomposition of humic substances in wastewater effluent. Bull. Korean Chem. Soc. 22(10) 1093-1110. 